\title{
Tiroidite subaguda, uma causa incomum de odinofagia: relato de caso
}

Joana Malta, ${ }^{1}$ Ana Catarina Matos, ${ }^{2}$ Daniela Malta, ${ }^{3}$ Jorge Portugal ${ }^{2}$

\section{RESUMO}

Introdução: A tiroidite subaguda, ou tiroidite de De Quervain, é uma patologia incomum. Uma das possíveis apresentações clínicas é a dor cervical anterior, com irradiação à orofaringe, condicionando odinofagia, sintoma este muito frequente nos cuidados de saúde primários. Este caso demonstra a importância de conhecer esta entidade como diagnóstico diferencial de odinofagia, sobretudo na presença de sintomas e sinais sugestivos de tirotoxicose.

Descrição do caso: Senhora de 36 anos, que iniciou quadro de febre, odinofagia e tumefação cervical, com três dias de evolução, inicialmente tratada como infeção das vias aéreas superiores. Uma vez que não se observou melhoria, foi novamente avaliada tendo sido identificada clínica sugestiva de doença tiroideia. O diagnóstico de tiroidite subaguda teve por base a presença de parâmetros analíticos de inflamação e de tirotoxicose, bem como a exclusão de patologia autoimune e bacteriana. O plano terapêutico envolveu o controlo sintomático e terapêutica anti-inflamatória, com boa evolução dos sintomas ao longo de semanas. Posteriormente, a doente desenvolveu hipotiroidismo, tendo sido controlada com terapêutica com levotiroxina.

Comentário: O diagnóstico precoce da tiroidite subaguda poderá não ser fácil pela sua apresentação inicial, podendo sugerir tratar-se de uma faringite comum. Apesar de ser um diagnóstico incomum, na presença de odinofagia/desconforto cervical e febre é essencial considerá-lo e pesquisar outros sintomas/sinais sugestivos desta doença. Diagnosticando precocemente, é possível minimizar o desconforto do doente e o consumo de recursos em saúde.

Palavras-chave: Tiroidite subaguda; Odinofagia; Tirotoxicose.

\section{INTRODUÇÃO}

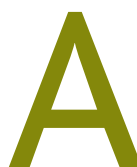
tiroidite subaguda, ou tiroidite de De Quervain, de presumível origem viral ou pós-viral, é uma condição rara com uma incidência anual estimada nos Estados Unidos da América de 12,1/100.000 casos. $^{1}$ Está descrita com uma maior incidência em mulheres jovens. ${ }^{1-2}$

O médico de família (MF), por se encontrar na linha da frente de cuidados de saúde, é aquele que mais frequentemente poderá contactar com esta patologia, sobretudo na sua fase clínica inicial mais inespecífica.

Os sintomas iniciais são frequentemente atribuídos ao foro otorrinolaringológico. ${ }^{3-4}$ Por este motivo, a tiroidite subaguda é muitas vezes subdiagnosticada. A forma clássica manifesta-se por dor e tumefação cervi-

1. USF Rio de Mouro

2. Hospital Garcia de Orta

3. USF Amora Saudável cal, desconforto este que pode irradiar à orofaringe e ouvidos. A febre baixa, fadiga, mialgias e artralgias são igualmente comuns. Os sintomas de hipertiroidismo/tirotoxicose manifestam-se, em metade dos doentes, nas primeiras semanas da doença. A glândula tiroideia apresenta-se aumentada e firme à palpação, tipicamente simétrica. A fase sintomática da doença atinge por norma o seu pico aos três-quatro dias, com melhoria ao longo das três a seis semanas seguintes. ${ }^{3}$

$\mathrm{Na}$ fase aguda da doença, do ponto de vista analítico, estão presentes parâmetros inflamatórios elevados (VS e PCR) e hipertiroidismo clínico. As alterações coincidentes com hipertiroidismo devem ser na verdade interpretadas como um estado de tirotoxicose, uma vez que na sua génese não está a produção aumentada, mas a destruição folicular com libertação de hormonas tiroideias. ${ }^{1,3,5}$

A ecografia da tiroide tem um papel fundamental no diagnóstico diferencial, para exclusão de tiroidite agu- 
da (supurativa) e da hemorragia de nódulo tiroideu. Raramente as tiroidites autoimunes (Hashimoto e Graves) podem também apresentar-se com dor cervical, por isso é importante a avaliação dos anticorpos. ${ }^{1}$

Este caso ilustra uma das formas de apresentação da tiroidite subaguda, passível de se confundir com um quadro de faringite comum. Demonstra a importância de uma anamnese e observação clínica abrangentes perante a queixa frequente de desconforto cervical e/ou odinofagia.

\section{DESCRIÇÃO DO CASO}

Utente do sexo feminino, 36 anos, sem antecedentes pessoais e familiares relevantes. Iniciou quadro de febre, odinofagia, tumefação cervical e mialgias, com três dias de evolução. Foi observada em contexto de centro de saúde e medicada inicialmente com ibuprofeno $400 \mathrm{mg}$ de $8 / 8 \mathrm{~h}$ e, por persistência e agravamento das queixas, após três dias com amoxicilina 500mg de 8/8h. Após quatro dias do início da antibioterapia recorreu novamente, desta vez em contexto de serviço de urgência. Referia agravamento da dor, associada a sensação de aperto cervical. Além das queixas anteriores, referia também história recente de tremor das mãos, palpitações, maior sudação e astenia. À observação apresentava taquicardia, hipertensão arterial, mãos quentes e suadas, tremor distal. A tiroide era palpável, de grandes dimensões, de consistência firme e dolorosa, sem rubor local (Figuras 1 e 2). O estudo analítico revelou leucocitose com neutrofilia, elevação da PCR e TSH suprimida.

A doente teve alta orientada para a consulta de endocrinologia que decorreu no dia seguinte. Foram pedidos adicionalmente anticorpos antitiroideus que se revelaram negativos e confirmaram-se valores de TSH e de T4 e T3 livre concordantes com tirotoxicose. Realizou também ecografia tiroideia, que revelou aumento difuso da glândula, sem outras alterações inclusive no estudo doppler. Perante a elevação dos parâmetros inflamatórios e após exclusão de patologia autoimune e bacteriana foi assumido o diagnóstico de tiroidite subaguda.

Iniciou terapêutica com prednisolona $20 \mathrm{mg}$ duas vezes ao dia e propranolol 20mg três vezes ao dia para controlo dos sintomas, tendo-se observado uma regressão da tumefação cervical e odinofagia em duas se-

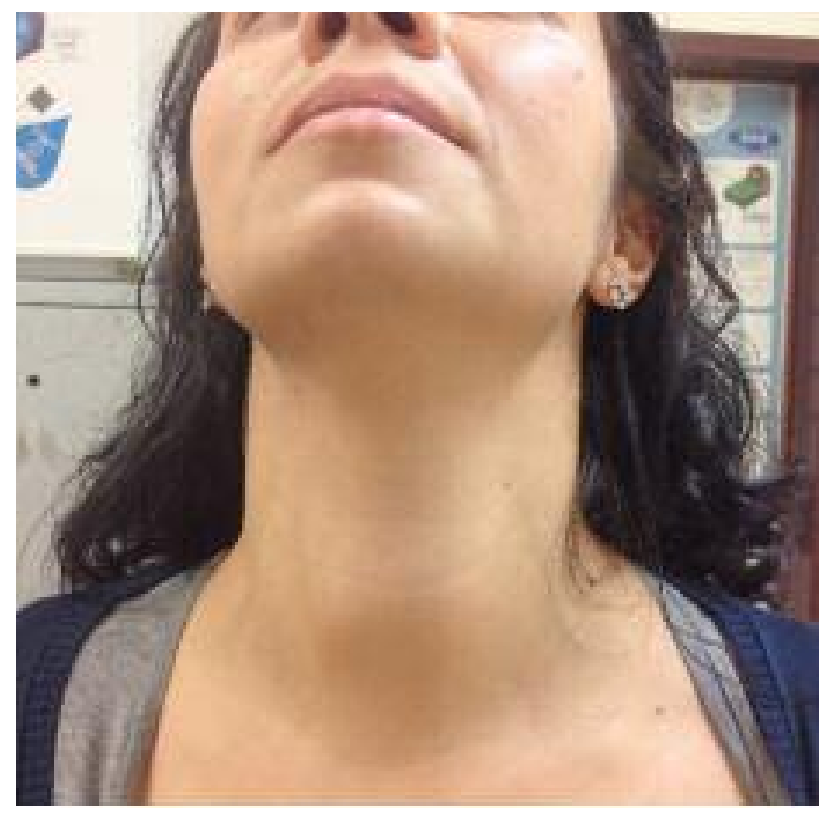

Figura 1. Evidência da tumefação cervical (de frente).

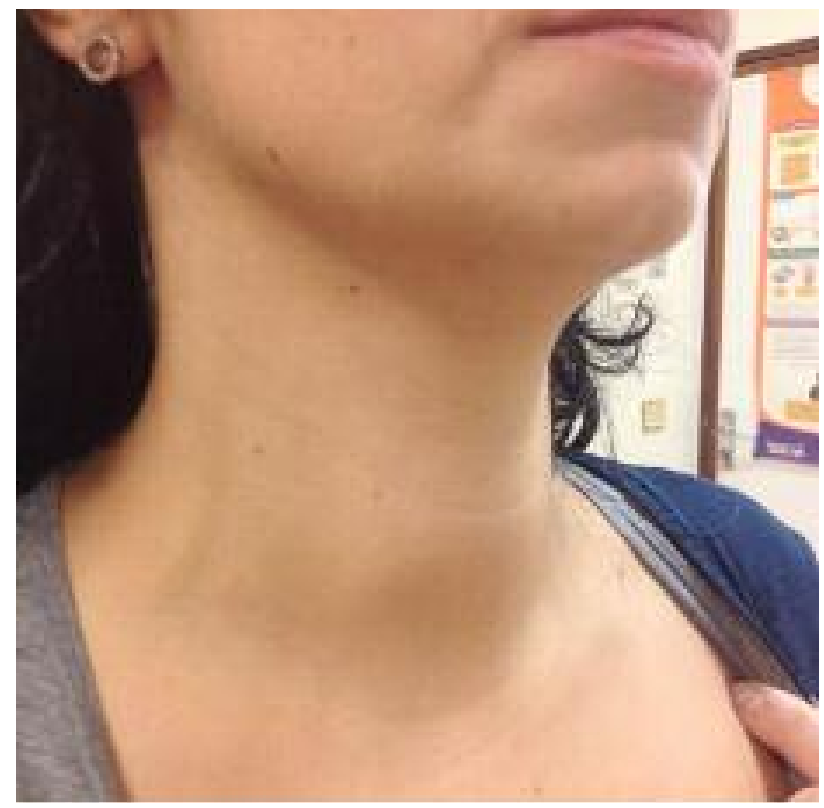

Figura 2. Evidência da tumefação cervical (de perfil).

manas. Manteve a terapêutica corticosteroide durante três meses, com descontinuação paulatina, acompanhada de melhoria dos sintomas de tirotoxicose e da função tiroideia. Mais tarde desenvolveu hipotiroidismo clínico e atualmente encontra-se estabilizada sob terapêutica com levotiroxina. 


\section{COMENTÁRIO}

Este caso ilustra uma situação de subdiagnóstico de tiroidite subaguda condicionada pela sintomatologia de início abrupto, sugestiva de uma faringite comum, como descrito na literatura. ${ }^{1}$ A sua etiologia é presumivelmente por infeção viral ou pós-viral e a maioria dos doentes apresenta história de infeção respiratória das vias superiores antes do início da tiroidite (geralmente de duas a oito semanas). ${ }^{1,4} \mathrm{~A}$ apresentação clínica pode ser variada e, por isso, o diagnóstico diferencial da tiroidite de De Quervain é vasto, incluindo o abcesso dentário, a faringite, a otite, entre outras situações de infeção respiratória alta. ${ }^{5}$ Foram descritos casos cujo único sintoma era febre de origem desconhecida..$^{5-6}$

O facto do tremor, taquicardia e sudação desta doente terem surgido mais tardiamente que a febre e a dor pode ter contribuído para a falha diagnóstica inicial. A evolução natural da doença, com o início das manifestações de tirotoxicose, e a não melhoria com a terapêutica dirigida a uma infeção das vias aéreas superiores, justificou equacionar outras hipóteses diagnósticas, nomeadamente de patologia tiroideia.

Para efeitos de diagnóstico diferencial do quadro desta doente, os autores que a observaram tiveram em consideração sobretudo a tiroidite aguda (supurativa), a hemorragia de nódulo tiroideu e as tiroidites autoimunes. A primeira hipótese apresenta-se geralmente com eritema local$^{2}$ para além de dor muito intensa, esta última também comum em situação de hemorragia de nodulo tiroideu..$^{2-3,7-8}$ Nestes casos, o estudo ecográfico da tiroide revela uma coleção abecedada ou um foco hemorrágico na tiroidite aguda e na hemorragia de nódulo tiroideu, respetivamente, o que não se verificou neste caso. A presença de anticorpos antitiroideus negativos permitiu a exclusão de tiroidites autoimunes, nomeadamente a doença de Graves, que é a causa mais frequente de hipertiroidismo. ${ }^{9} \mathrm{O}$ estudo doppler também foi útil nesta situação para exclusão de doença de Graves, dado que é habitual um aumento da vascularização da glândula tiroideia. Assim, perante a evolução do quadro clínico e a exclusão das hipóteses diagnósticas referidas foi estabelecido o diagnóstico de tiroidite de De Quervain.

Sendo uma patologia autolimitada, o tratamento visa melhorar a dor e tumefação cervical bem como os sintomas decorrentes da tirotoxicose..$^{1,3,5-6} \mathrm{Na}$ terapêutica farmacológica poderão ser usados anti-inflamatórios não-esteroides (AINE), salicilatos e corticosteroides por um período recomendado de oito semanas. ${ }^{1,5}$ Os beta-bloqueantes estão indicados no tratamento dos sintomas da tirotoxicose, quando presentes. ${ }^{3,6,8}$ Os fármacos antitiroideus não têm indicação, uma vez que a sua etiopatogenia não está relacionada com a produção aumentada de hormonas tiroideias. ${ }^{3,5}$

Nesta doente optou-se por terapêutica com prednisolona, dado a terapêutica inicial com AINE não ter resultado em melhoria sintomática. ${ }^{3}$ Apesar dos corticosteroides reduzirem a inflamação e, consequentemente, a dor associada à tiroidite de De Quervain, nem sempre evitam a disfunção tiroideia que pode ocorrer no decurso da doença. Frequentemente é necessário o tratamento dos sintomas da tirotoxicose com propranolol ou atenolol. ${ }^{3,5}$

O seguimento destes doentes é muito importante, dada a possibilidade de recorrência da doença na fase de descontinuação da corticoterapia. Estima-se que possa ocorrer em $20 \%$ dos casos, daí que seja recomendado um período de tratamento mínimo de seis semanas e descontinuação paulatina ao longo de duas semanas. ${ }^{3}$ A função tiroideia deve ser monitorizada a cada duas a oito semanas para confirmar a sua normalização. ${ }^{1}$ Pode seguir-se um período de hipotiroidismo que, em $10 \%$ dos casos, se torna permanente, ${ }^{3}$ como ocorreu nesta doente. Nesta fase é possível o MF monitorizar a função tiroideia e fazer os devidos ajustes terapêuticos.

Este caso veio reforçar a ideia de que, embora a anamnese e o exame objetivo possam ser os mais adequados, o diagnóstico de tiroidite de De Quervain geralmente é tardio devido à sua apresentação clínica inicial pouco específica. Permitiu também rever a sua abordagem diagnóstica e terapêutica. Por fim, este caso alerta para que a tiroidite subaguda não seja esquecida, embora incomum. Só assim poderá ser tida em conta como hipótese diagnóstica e referenciada precocemente, minorando o sofrimento do doente e o consumo de recursos em saúde.

\section{REFERÊNCIAS BIBLIOGRÁFICAS}

1. Burman KD. Subacute thyroiditis. In: UpToDate [Internet]; 2018 Jan 2. Available from: https://www.uptodate.com/contents/subacute-thyroiditis?search=subacute $\% 20$ thyroiditis\&source=search_result \&selec- 
tedTitle $=1 \sim$ 30\&usage_type $=$ default $\&$ display_rank $=1$

2. Slatosky J, Shipton B, Wahba H. Thyroiditis: differential diagnosis and management. Am Fam Physician. 2000;61(4):1047-54.

3. Hennessey J. Subacute thyroiditis. In: Feingold KR, Anawalt B, Boyce A, et al., editors. Endotext [Internet]. South Dartmouth (MA): MDText.com; 2018. Available from: https://www.ncbi.nlm.nih.gov/books/NBK279084/

4. Michas G, Alevetsovitis G, Andrikou I, Tsimiklis S, Vryonis E. De Quervain thyroiditis in the course of H1N1 influenza infection. Hippokratia. 2014;18(1):86-7.

5. Tabassom A, Edens MA. De Quervain thyroiditis [Internet]. Treasure Island (FL): StatPearls Publishing; 2019. Available from: https://www. ncbi.nlm.nih.gov/books/NBK526066/

6. Das S. Subacute thyroiditis: an uncommon cause of fever of unknown origin. Indian J Endocrinol Metab. 2012;16(Suppl 2):S340-1.

7. Ross DS. Cystic thyroid nodules. In: UpToDate [Internet]; 2018 Apr 25. Available from: https://www.uptodate.com/contents/cystic-thyroidnodules?search=Cystic\%20thyroid\%20nodules\&source=search_result\&selectedTitle=1 32\&usage_type=default\&display_rank=1
8. Alfadda AA, Sallam RM, Elawad GE, Aldhukair H, Alyahya MM. Subacute thyroiditis: clinical presentation and long term outcome. Int J Endocrinol. 2014;2014:794943.

9. Cui Z, Wang Z, Liu X, Cai Y, Xu X, Yang T. Establishment of clinical diagnosis model of Graves' disease and Hashimoto's thyroiditis. J Transl Med. 2019;17:11.

\section{CONFLITO DE INTERESSES}

Os autores declaram não ter conflitos de interesses.

\author{
ENDEREÇO PARA CORRESPONDÊNCIA \\ Joana Malta \\ E-mail: joanamlta@gmail.com \\ https://orcid.org/0000-0002-2106-7445
}

Recebido em 08-01-2017

Aceite para publicação em 08-02-2019

\section{ABSTRACT}

\section{SUBACUTE THYROIDITIS, AN UNCOMMON CAUSE OF ODYNOPHAGIA: CASE REPORT}

Introduction: Subacute thyroiditis, or De Quervain's thyroiditis, is an uncommon condition. It can manifest itself as an anterior neck pain with radiation into the oropharynx, leading to odynophagia, a very common symptom in primary care. This case report demonstrates the importance of being aware of this clinical entity as a differential diagnosis of odynophagia, particularly when in presence of symptoms and signs of thyrotoxicosis.

Case description: 36-years old female, presenting with fever, odynophagia sore throat and swollen neck, initially treated as an upper respiratory tract infection. Since no clinical improvement was observed, the patient was re-assessed and clinical signs of thyroid pathology were identified. The diagnosis of subacute thyroiditis was based on biochemical markers of inflammation and thyrotoxicosis, as well as on the exclusion of autoimmune and bacterial causes. The treatment plan included symptomatic control with anti-inflammatory drugs, with improvement of symptoms over the following weeks. Subsequently, the patient developed an hypothyroidism and was treated with levothyroxine therapy.

Comment: The early diagnosis of subacute thyroiditis may not be easy due its initial presentation, and may suggest a common pharyngitis. Although being an uncommon diagnosis, this diagnosis should be considered when in presence of odynophagia / neck pain and fever and other symptoms/signs should be searched, in order to minimise patient discomfort and healthcare resources' spending.

Keywords: Thyroiditis, subacute; Sore throat; Thyrotoxicosis; Odynophagia. 